\title{
Retrospective Cohort Study on Acute Care in Obstetrics and Gynecology: Analogies and Differences When Compared to Emergency Medicine
}

\author{
Giuseppe Chiossi ${ }^{1}$, Stefano Palomba ${ }^{2}$, Sara Balduzzi ${ }^{3}$, Maged M. Costantine ${ }^{1}$, Angela I. Falbo ${ }^{2}$, \\ Anna M. Ferrari ${ }^{4}$, Giovanni B. La Sala ${ }^{2,5}$ \\ ${ }^{1}$ Department of Obstetrics and Gynecology, University of Texas Medical Branch, Galveston, TX, USA \\ ${ }^{2}$ Department of Obstetrics and Gynecology, Arcispedale Santa Maria Nuova, IRCCS, Reggio Emilia, Italy \\ ${ }^{3}$ Statistics Unit, Department of Oncology, Hematology and Respiratory Diseases, University of Modena and Reggio Emilia, \\ Modena, Italy \\ ${ }^{4}$ Department of Emergency Medicine, Arcispedale Santa Maria Nuova, IRCCS, Reggio Emilia, Italy \\ ${ }^{5}$ University of Modena and Reggio Emilia, via Università 4, Modena, Italy \\ Email: gichioss@utmb.edu
}

How to cite this paper: Chiossi, G., Palomba, S., Balduzzi, S., Costantine, M.M., Falbo, A.I., Ferrari, A.M. and La Sala, G.B. (2017) Retrospective Cohort Study on Acute Care in Obstetrics and Gynecology: Analogies and Differences When Compared to Emergency Medicine. Open Journal of Obstetrics and Gynecology, 7, 473485 .

https://doi.org/10.4236/ojog.2017.74049

Received: April 3, 2017

Accepted: April 27, 2017

Published: April 30, 2017

Copyright $\odot 2017$ by authors and Scientific Research Publishing Inc. This work is licensed under the Creative Commons Attribution International License (CC BY 4.0).

http://creativecommons.org/licenses/by/4.0/ (c) (i) Open Access

\begin{abstract}
Introduction: the demand for urgent obstetric and gynecology care has progressively increased: in the United States approximately 1.4 million gynecologic visits are made to the emergency department (ED) annually, while almost $75 \%$ of women make at least 1 unscheduled visit during pregnancy. Moreover, research has recently focused on setting standards in unscheduled care, and developing quality indicators to improve patients' health. Therefore, we investigated the characteristics of women with acute gynecological or pregnancy complaints using quality indicators developed for emergency medicine, to better define the needs of this population and improve care. $\mathbf{M e}$ thods. Retrospective cohort study on ED, and Obstetrics and Gynecology (ObGyn) triage visits, at a tertiary care hospital in Italy, during 2012. Data were analyzed with population-averaged logistic regression and Poisson regression. Results. When compared to the 33,557 ED visits, the 9245 ObGyntriage referrals were more frequently associated with pregnancy ( $\leq 12$ weeks' gestation, OR: 30.7, 95\%CI; 24.5 - 38.4; >12 weeks' gestation, OR 81.2, 95\%CI; 64.8 - 101.4), vaginal bleeding (OR 156.6, 95\%CI; 82.7 - 294.4), diurnal (night access OR $0.87,95 \% \mathrm{CI} ; 0.78-0.96$ ) and weekday access (holiday access OR $0.87,95 \% \mathrm{CI} ; 0.78$ - 0.95), frequent users (recurrent $\mathrm{ED}$ visits IRR $0.87,95 \% \mathrm{CI}$; 0.83 - 0.9) and lower hospital admissions (ED admission OR 1.6, 95\%CI; 1.4 1.8). Conclusion: ObGyn triage patients differed from ED users, and were at higher risk of "crowding". Such diversities should be considered to improve female healthcare services and allocate resources more efficiently.
\end{abstract}




\section{Keywords}

Acute Care, Obstetric Urgencies, Gynecologic Urgencies,

Obstetrics and Gynecology Triage, Emergency Department

\section{Introduction}

The practice of obstetrics and gynecology has traditionally been divided into acute and elective services. Although labor and delivery units address most acute complaints of pregnant women in the $2^{\text {nd }}$ and $3^{\text {rd }}$ trimester [1] [2], women experiencing pelvic pain or vaginal bleeding traditionally present to emergency departments (ED) where, after an initial assessment, they are often evaluated by an on-call obstetrician-gynecologist. The demand for urgent obstetric and gynecology care has progressively increased: in the United States approximately 1.4 million gynecologic visits are made to the ED annually [3], 13\% of ambulatory visits for gynecological conditions occur in urgent care centers or EDs [4], while almost $75 \%$ of women make at least 1 unscheduled visit during pregnancy [5]. Moreover, management of acute gynecological and early pregnancy complaints has recently changed. In the United Kingdom and Australia, the introduction of combined early pregnancy and acute gynecological units led to a drop in hospital admissions, improved patients' satisfaction, accounted for significant cost savings and decreased ED occupancy [6] [7] [8]. In France and Italy, similar results were obtained by hospital-based emergency services run by obstetriciangynecologists [9] [10].

Striking similarities exist between emergency medicine physicians and obstetrician-gynecologists: caring for unscheduled patients with urgent health problems, dealing with unanticipated crises, facing circadian disruption, coping with medical legal liability and work related stress are only few of the features these providers share [11] [12] [13].

Unscheduled care has been under sustained pressure to set standards and develop quality indicators to improve patients' health. Recently, ED performance indicators have been reviewed in order to better define how well health services meet desirable outcomes [14]. As quality indicators have not been standardized for acute female care, we compared women with acute gynecological and pregnancy complaints with ED patients, and we also investigated how return visits and hospital admission rates, two of the most studied ED performance indicators [14], characterize care in obstetrics and gynecology. We sought to study access to emergency female services using standards developed in emergency medicine, in order to better understand the needs of this population and improve care.

\section{Materials and Methods}

\subsection{Study Population and Setting}

We conducted a retrospective cohort study on ED accesses and obstetrics and gynecology (ObGyn) triage visits from January $1^{\text {st }}$ until December $31^{\text {st }} 2012$, in a 
tertiary care hospital. Data are reported in accordance with STROBE guidelines. Arcispedale Santa Maria Nuova Hospital, is a referral center that, along with 4 satellite hospitals, serves a population of more than 500,000 in Reggio Emilia county, Italy. The hospital is a level II trauma center, and includes an ED, a labor and delivery unit, an ObGyn triage, inpatient and outpatient services for pregnant women and women with gynecological complications, as well as a level III neonatal intensive care unit.

All women evaluated in the ED or the ObGyn triage throughout 2012 were included in the study: they could present on their own initiative, after referral from other physicians (such as general practitioners, or obstetrician-gynecologists), or by ambulance. Typically, an ED triage nurse directs pregnant patients with non-urgent complaints, and women with gynecological conditions not requiring immediate attention to the ObGyn triage; if prompt intervention is needed, patients are stabilized by ED physicians as the obstetrician-gynecologists on call are notified. Emergency room staff can consult obstetrician-gynecologists when needed. Similarly, women with acute complaints and a negative evaluation at the ObGyn triage can be referred to the ED.

\subsection{Healthcare Providers}

Eleven physicians with shifts ranging from 4 to 12 hours staff the ED 24-hour a day, along with 12 registered nurses (RNs) on 6-hour duty periods. The ObGyn triage consists of two separate units with ultrasound capabilities. One unit ("gynecology triage") mainly evaluates women presenting with acute gynecological complaints (i.e. abdominal or pelvic pain, lower genital tract symptoms) or compelling symptoms related to nonviable pregnancy (i.e. vaginal bleeding or abdominal pain in patients diagnosed with missed abortion, incomplete abortion or suspect ectopic pregnancy). The other ("obstetrics triage") addresses pregnant women with urgent issues (i.e. uterine contractions, leakage of fluid, reduced fetal movements, vaginal discharge). Two obstetrician-gynecologists proficient in transvaginal and basic obstetric ultrasound provide in-house coverage on 12 hour shifts (from 8 am to $8 \mathrm{pm}$, and from $8 \mathrm{pm}$ to $8 \mathrm{am}$ ). One physician manages laboring women, evaluates accesses to the obstetrics triage, and addresses hospitalized pregnant and postpartum patients. The other evaluates referrals to the gynecology triage, manages gynecology consults, and addresses the inpatient gynecology service. The two providers work jointly, especially in case of operative or cesarean deliveries, emergent surgeries or high workload. Referrals to the obstetrics and to the gynecology triage overlap to some extent, especially when users are pregnant women in the first trimester. At all times, 4 certified nurse midwives (CNMs) staff the labor and delivery unit and the obstetrics triage, 3 CNMs provide care to the antepartum and postpartum service, while 3 registered nurses $(\mathrm{RN})$ cover the inpatient gynecology service and triage.

\subsection{Study Protocol}

We individually reviewed the electronic medical records of all ED visits, as well 
as all ObGyn triage accesses from 2012. We extended the study period to 1 year to account for the seasonal differences in ED access [15]; a specific sample size calculation was not performed due to the large study population. The study was approved by Arcispedale Santa Maria Nuova Hospital Institutional Review Board. Patients' consent to study participation and publication of unidentified data was managed according to the Personal Data Protection Act and the Guidelines on Personal Data Management in Clinical Studies [16] [17]. Both ED and ObGyn triage visits were classified into the following 5 categories: 1) pregnancy $\leq 12$ weeks' gestation (including also non viable pregnancies such as incomplete abortions, missed abortions, or ectopic pregnancies), 2) pregnancy $>12$ weeks' gestation, 3) abdominal or pelvic pain affecting non-pregnant women 4) vaginal bleeding not associated with pregnancy, 5) other reasons prompting non pregnant patients to access emergency health services. Such classification reflected our intention to differentiate between acute obstetric issues from gynecologic complications, and summarized the most prevalent reasons for referral to triage, as demonstrated by a preliminary review of 50 obstetrics and 50 gynecology triage records from 2011. A distinction between gestational ages $\leq 12$ and $>12$ weeks was made, as the type of obstetrical complications and the level of pregnancy worries change throughout gestation [18].

\subsection{Study Protocol}

Statistical analyses were performed using Stata 13.1 (StataCorp, College Station, TX, US). Descriptive statistics were used to characterize the demographic information of the study population. To identify potential predictors of emergency health care accesses and hospital admissions, categorical variables were tested with Chi square test or Fisher's exact test as appropriate, while continuous data were compared with Wilcoxon rank-sum test, One way ANOVA, or One way ANOVA on ranks as indicated. A level of statistical significance of $p \leq 0.05$ was considered.

Women's age, ethnicity, and chief complaint, as well as time, day and season of the visits were studied to characterize ObGyn and ED accesses. When recurrent use of emergency resources and hospital admissions were investigated, the type of acute care utilized (ObGyn vs. ED) was also accounted for.

Population-averaged logistic regression models with an exchangeable correlation matrix and a robust variance estimator were used to identify the predictors of ObGyn triage vs ED visits, as well as hospital admissions. The models accounted for repeated measures for each participant. Quasilikelihood under the independence model criterion (QIC), and its simplified version $\left(\mathrm{QIC}_{\mathrm{U}}\right)$ were used to determine the best-working correlation structure [19] [20]: the final models presented the smallest QIC and $\mathrm{QIC}_{\mathrm{U}}$ values.

Poisson regression was used to address the distribution of emergency health services return visits. Frequent users were defined as having $\geq 2$ visits in the study period; this definition was based on the distribution of return visits in our sample, and it is within the range of what was previously reported in the litera- 
ture on frequent ED users [21]. Akaike's Information Criterion (AIC), and Bayesian Information Criterion (BIC) were used to select the final model [22] [23].

Candidate variables for the previous models were included if significantly different on univariate analysis or clinically relevant. The following interactions were also considered a priori, and displayed if significant: chief complaint and ethnicity, chief complaint and age, ethnicity and time of emergency access, weekday/holiday access and time, weekday/holiday access and chief complaint.

\section{Results}

During the study period women accounted for 42,802 accesses to emergency services: 33,557 (78.4\%) to the ED, and 9245 (21.6\%) to the ObGyn triage.

Table 1 presents the demographic characteristics of the study population, along with the multivariate analysis on ED vs. ObGyn triage visits. Overall, women presenting to triage were younger, were less likely to be Caucasian, presented more frequently at night ( $8 \mathrm{pm}$ to $8 \mathrm{am})$, and on weekdays $(p<0.001)$. Moreover, triage accesses were more commonly due to pregnancy, vaginal bleeding, or abdominal pain $(p<0.001)$. In the multivariate analysis, triage use was associated with pregnancy $(p<0.001)$, vaginal bleeding $(p<0.001)$, diurnal $(p=0.007)$, and weekday access $(p=0.005)$ as opposed to ED use. A quadratic relation was also discovered between women's age and type of emergency services $(p<0.001)$ (Figure 1 ).

Seven thousand nine hundred four out of 28913 (27.3\%) patients with acute complaints had $\geq 2$ emergency services accesses throughout 2012. Table 2 summarizes the univariate and multivariate analysis on multiple accesses to the ED only, the ObGyn triage only, and both services respectively. Focusing on female reproductive history, age was categorized according to the average age at menarche and menopause [24] [25]. If recurrent visits were due to conditions that changed over time, "multiple causes" was indicated as the reason for referral. Overall, the 3 study groups differed in terms of race, age, chief complaint, as well as time distribution of accesses $(p<0.001)$. In selecting covariates for the multivariate analysis, we could not include both the type of emergency healthcare service utilized and the reason for referral due to collinearity. As they were both considered fundamental determinants of multiple accesses, we built two different models, respectively centered on the type of resources utilized (model 1) and on the patients' complaints (model 2). Using both models, correlates of being a frequent user included older age (that reached significance only $\geq 51.4$ years, $p=0.04)$, presenting at any time of the day, of the week, and on any season $(p<0.001)$. When compared to women with exclusive ObGyn triage visits, frequent users were less likely to present only to the $\operatorname{ED}(p<0.001$, model 1$)$, and more likely to access both services $(p=0.01$, model 1$)$. Moreover, pregnancy ( $\leq 12$ weeks' gestation, $p<0.001$; $>12$ weeks' gestation, $p=0.01$; model 2 ) and multiple complaints $(p<0.001$, model 2$)$ were more represented among frequent users. 
Eight thousand one hundred six out of 42,802 (19\%) emergency services visits turned into hospital admissions. Overall, women admitted as inpatients accessed mainly the ObGyn triage, were younger, Caucasian, had more emergency visits, used healthcare services more at night $(8 \mathrm{pm}$ to $8 \mathrm{am})$ and on weekdays $(p<$ 0.001) (Table 3). Moreover, hospital admissions were more common among pregnant women $>12$ gestational weeks, and among subjects with abdominal pain $(p<0.001)$. In the multivariate analysis, hospital admissions were associated with ED visits, patients' age, number of emergency visits, night time resource utilization, and pregnancy $>12$ weeks' gestation $(p<0.001)$. A significant interaction between time of arrival and race was detected: non-Caucasian females

Table 1. Accesses to emergency health services.

\begin{tabular}{|c|c|c|c|c|c|}
\hline & \multicolumn{3}{|c|}{ Univariate analysis } & \multicolumn{2}{|c|}{$\begin{array}{c}\text { Multivariate analysis Population averaged model } \\
\text { Outcome: ObGynvs. ED referral }\end{array}$} \\
\hline & ObGyn triage & ED & & OR, $(95 \% \mathrm{CI})$ & \\
\hline & ${ }^{\#} \mathrm{~N}=9245$ & ${ }^{*} \mathrm{~N}=33,557$ & $P$ Value & ${ }^{\circ \circ} \mathrm{N}=28,913$ & $P$ Value \\
\hline Race & & & $<0.01^{*}$ & & \\
\hline Caucasian & $7066(76.4)$ & $30,460(90.8)$ & & - & - \\
\hline Other & $2179(23.6)$ & $3997(9.2)$ & & - & - \\
\hline Age & $32.3[27.1-37.5]$ & $52.7[33.2-69.8]$ & $<0.01^{\circ}$ & $1.08(1.07-1.09)$ & $<0.019$ \\
\hline Age square & - & - & & $0.9986(0.9984-0.9987)$ & $<0.019$ \\
\hline Reason for referral & & & $<0.01^{*}$ & & \\
\hline Pregnancy $\leq 12$ weeks & $1532(16.6)$ & $91(0.27)$ & & $30.7(24.5-38.4)$ & $<0.019$ \\
\hline Pregnancy > 12 weeks & $5195(56.2)$ & $72(0.2)$ & & $81.2(64.8-101.7)$ & $<0.019$ \\
\hline Vaginal bleeding & $766(8.3)$ & $18(0.05)$ & & $156.6(82.7-294.4)$ & $<0.019$ \\
\hline Abdominal pain & $642(6.9)$ & $2006(6)$ & & $1 \S$ & - \\
\hline Other & $1100(12)$ & $31,370(93.48)$ & & $0.12(0.1-0.13)$ & $<0.019$ \\
\hline Time & & & $<0.01^{*}$ & & \\
\hline Day (8 am to $8 \mathrm{pm})$ & $5962(64.5)$ & $23,955(71.5)$ & & $1 \S$ & - \\
\hline Night ( $8 \mathrm{pm}$ to $8 \mathrm{am})$ & $3283(35.5)$ & $9562(28.5)$ & & $0.87(0.78-0.96)$ & $0.007 g$ \\
\hline Weekday/Holiday & & & $<0.01^{*}$ & & \\
\hline Weekday & $6581(71.2)$ & $22,915(68.3)$ & & $1 \S$ & - \\
\hline Holiday & $2664(28.8)$ & $10642(31.7)$ & & $0.87(0.78-0.95)$ & $0.005 \mathrm{~g}$ \\
\hline Season & & & $0.01^{*}$ & & \\
\hline Winter & $2193(23.7)$ & $8266(24.6)$ & & - & - \\
\hline Spring & $2370(25.6)$ & $8855(26.4)$ & & - & - \\
\hline Summer & $2302(24.9)$ & $8308(24.8)$ & & - & - \\
\hline Fall & $2380(25.8)$ & $8128(24.2)$ & & - & - \\
\hline
\end{tabular}

ObGyn triage: obstetrics and gynecology triage; ED: emergency department. "Number of visits; ${ }^{\circ}$ Number of patients. Data presented as N (\%); §This group served as the reference group in the multivariate analysis chi square test, ${ }^{\circ}$ Wilcoxon rank-sum test, 9 Wald test. Population averaged model: the 42,802 referrals analyzed corresponded to the need for emergency heath services of 28,913 different patients; the average number of visits for each subject was 1.5 , ranging from 1 to 33 . QIC $=13,503, \mathrm{QIC}_{\mathrm{U}}=13,500$. 
Table 2. Frequent users: women with two or more accesses to emergency health services.

\begin{tabular}{|c|c|c|c|c|c|c|c|c|}
\hline & \multicolumn{4}{|c|}{ Univariate analysis } & \multirow{2}{*}{\multicolumn{2}{|c|}{$\begin{array}{c}\text { Multivariate analysis Poisson } \\
\text { regression Model } 1\end{array}$}} & \multirow{2}{*}{\multicolumn{2}{|c|}{$\begin{array}{l}\text { Multivariate analysis Poisson } \\
\text { regression Model } 2\end{array}$}} \\
\hline & ObGyn triage & $\mathrm{ED}$ & $\begin{array}{c}\text { ObGyn triage } \\
\text { \&ED }\end{array}$ & & & & & \\
\hline & ${ }^{\circ} \mathrm{N}=1531$ & ${ }^{\circ} \mathrm{N}=5373$ & ${ }^{\circ} \mathrm{N}=1000$ & $P$ Value & ${ }^{\circ} \mathrm{N}=7904$ & $P$ Value & ${ }^{\circ} \mathrm{N}=7904$ & $P$ Value \\
\hline ObGyn triage & - & - & - & & $1 \S$ & - & - & - \\
\hline ED & - & - & - & & $0.87(0.83-0.9)$ & $<0.001$ g & - & - \\
\hline ObGyn triage \& ED & - & - & - & & $1.06(1.01-1.2)$ & 0.01 & - & - \\
\hline Race & & & & $<0.01^{\star}$ & & & & \\
\hline Caucasian & $1176(76.8)$ & 4916 (91.5) & $734(73.4)$ & & - & - & - & - \\
\hline Other & $355(23.2)$ & $457(8.5)$ & $266(26.6)$ & & - & - & - & - \\
\hline Age & & & & $<0.01^{\star *}$ & & & - & - \\
\hline$<12.4$ & $3(0.2)$ & $150(2.8)$ & $3(0.3)$ & & $1 \S$ & - & $1 \$$ & - \\
\hline $12.4-51.4$ & $1510(98.62)$ & $2048(38.12)$ & $904(90.4)$ & & $1.1(0.9-1.2)$ & 0.1 & $1.1(0.9-1.2)$ & 0.19 \\
\hline$\geq 51.4$ & $18(1.18)$ & $3175(59.08)$ & $93(9.3)$ & & $1.12(1.007-1.2)$ & 0.04 & $1.11(1.006-1.2)$ & 0.04 \\
\hline \multicolumn{9}{|l|}{ Reason for referral } \\
\hline Pregnancy $\leq 12$ weeks & $374(24.4)$ & $12(0.22)$ & $0(0)$ & & - & - & $1.2(1.1-1.3)$ & $<0.019$ \\
\hline Pregnancy $>12$ weeks & $949(62)$ & $7(0.13)$ & $0(0)$ & & - & - & $1.11(1.02-1.2)$ & 0.019 \\
\hline Vaginal bleeding & $82(5.4)$ & $2(0.04)$ & $0(0)$ & & - & - & $1(0.9-1.2)$ & 0.5 \\
\hline Abdominal pain & $59(3.8)$ & $283(5.27)$ & $0(0)$ & & - & - & $1 \$$ & - \\
\hline Other & $67(4.4)$ & $5069(94.34)$ & $0(0)$ & & - & - & $1(0.9-1.1)$ & 0.69 \\
\hline Multiple Causes & $0(0)$ & $0(0)$ & $1000(100)$ & & - & - & $1.2(1.1-1.3)$ & $<0.019$ \\
\hline Time & & & & $<0.01^{*}$ & & & & \\
\hline Day (8 am to $8 \mathrm{pm})$ & $477(31.2)$ & $2594(48.3)$ & $340(34)$ & & $1 \S$ & - & $1 \$$ & - \\
\hline Night ( $8 \mathrm{pm}$ to $8 \mathrm{am})$ & $133(8.7)$ & $441(8.2)$ & $76(7.6)$ & & $0.95(0.89-1)$ & 0.08 & $0.95(0.89-1)$ & 0.08 \\
\hline Day \& Night & $921(60.1)$ & $2338(43.5)$ & $584(58.4)$ & & $1.23(1.19-1.26)$ & $<0.001$ & $1.22(1.19-1.26)$ & $<0.01$ \\
\hline Weekday/Holiday & & & & $<0.01^{*}$ & & & & \\
\hline Weekday & $634(41.4)$ & $2292(42.7)$ & $370(37)$ & & $1 \$$ & - & $1 \S$ & - \\
\hline Holiday & $106(6.9)$ & $479(8.9)$ & $72(7.2)$ & & $0.94(0.88-0.99)$ & $0.04 \mathrm{~g}$ & $0.94(0.89-0.99)$ & $0.03 \mathrm{~g}$ \\
\hline Weekday \& Holyday & $791(51.7)$ & $2602(48.4)$ & $558(55.8)$ & & $1.23(1.2-1.27)$ & $<0.001$ g & $1.23(1.2-1.27)$ & $<0.019$ \\
\hline Season & & & & $<0.01^{*}$ & & & & \\
\hline Winter & $188(12.3)$ & $471(8.8)$ & $51(5.1)$ & & $1 \$$ & - & $1 \S$ & - \\
\hline Spring & $208(13.6)$ & $498(9.3)$ & $51(5.1)$ & & $0.9(0.9-1.1)$ & 0.9 & $1(0.9-1.1)$ & 0.9 \\
\hline Summer & $186(12.1)$ & $484(9)$ & $57(5.7)$ & & $1(0.9-1.1)$ & 0.9 & $1(0.9-1.1)$ & 0.9 \\
\hline Fall & $191(12.5)$ & $432(8)$ & $58(5.8)$ & & $1(0.9-1.1)$ & 0.9 & $1(0.9-1.1)$ & 0.9 \\
\hline Multiple seasons & $758(49.5)$ & $3488(64.9)$ & $783(78.3)$ & & $1.2(1.1-1.3)$ & $<0.001$ & $1.24(1.18-1.31)$ & $<0.01$ \\
\hline
\end{tabular}

$\S$ This group served as the reference group in the multivariate analysis; ${ }^{\circ}$ Number of patients (\%); ${ }^{*}$ chi square test, ${ }^{* *}$ Fisher's exact test, $\mathbf{g}$ Wald test; ObGyn triage: obstetrics and gynecology triage; ED: emergency department; Poisson regression: Akaike’s Information Criterion (AIC) $=3255$, and Bayesian Information Criterion $(\mathrm{BIC})=-45,082$ for model $1, \mathrm{AIC}=3255$ and BIC $-45,064$ for model 2 . 
Table 3. Hospital admissions through the emergency department or the obstetrics and gynecology triage.

\begin{tabular}{|c|c|c|c|c|c|}
\hline & \multicolumn{3}{|c|}{ Univariate analysis } & \multicolumn{2}{|c|}{$\begin{array}{l}\text { Multivariate analysis Population averaged model Outcome } \\
\text { hospital admission }\end{array}$} \\
\hline & Admission & No admission & & Odds Ratio (OR, 95\% CI) & \\
\hline & ${ }^{\#} \mathrm{~N}=8106$ & ${ }^{\#} \mathrm{~N}=34,696$ & P Value & ${ }^{\circ} \mathrm{N}=28,913$ & $P$ Value \\
\hline Emergency Service & & & $<0.01^{*}$ & & \\
\hline ObGyn Triage & $2616(32.3)$ & $6629(19.1)$ & & $1 \S$ & - \\
\hline $\mathrm{ED}$ & $5490(67.7)$ & $28,067(80.9)$ & & $1.6(1.4-1.8)$ & $<0.019$ \\
\hline Race & & & $<0.01^{*}$ & & \\
\hline Caucasian & $6977(86)$ & $30,549(88)$ & & $1 \S$ & - \\
\hline Other & $1129(14)$ & $4147(12)$ & & $0.9(0.8-1.1)$ & 0.29 \\
\hline Age & $39.6[30.1-66.7]$ & $43.7[30-70.3]$ & $<0.01^{\circ}$ & $1.003(1.002-1.004)$ & $<0.019$ \\
\hline Reason for referral & & & $<0.01^{*}$ & & \\
\hline Pregnancy $\leq 12$ weeks & $120(1.5)$ & $1503(4.4)$ & & $0.6(0.5-0.8)$ & $<0.019$ \\
\hline Pregnancy > 12 weeks & $2261(27.9)$ & $3006(8.6)$ & & $5.4(4.6-6.3)$ & $<0.019$ \\
\hline Vaginal bleeding & $89(1.1)$ & $695(2)$ & & $0.8(0.6-1)$ & $0.09 g$ \\
\hline Abdominal pain & $519(6.4)$ & $2129(6.1)$ & & $1 \S$ & - \\
\hline Other & $5117(63.1)$ & $27,363(78.9)$ & & $0.77(0.7-0.83)$ & $<0.019$ \\
\hline Time & & & $<0.01^{*}$ & & \\
\hline Day (8 am to $8 \mathrm{pm})$ & $5242(64.7)$ & $24,715(71.2)$ & & $1 \S$ & - \\
\hline Night (8 pm to 8 am) & $2864(35.3)$ & $9981(28.8)$ & & $1.23(1.17-1.29)$ & $<0.019$ \\
\hline \multicolumn{6}{|l|}{ Interaction } \\
\hline \multicolumn{6}{|l|}{ Time \& Ethnicity } \\
\hline Caucasia \& Day & - & - & & $1 \S$ & - \\
\hline Other \& Night & - & - & & $1.3(1.1-1.5)$ & 0.029 \\
\hline Weekday/Holiday & & & $<0.01^{*}$ & & \\
\hline Weekday & $5644(69.6)$ & $23,852(68.7)$ & & - & - \\
\hline Holiday & $2462(30.4)$ & $10,844(31.3)$ & & - & - \\
\hline Season & & & $0.2^{*}$ & & \\
\hline Winter & $1936(23.9)$ & $8523(24.6)$ & & - & - \\
\hline Spring & $2079(25.6)$ & $9146(26.4)$ & & - & - \\
\hline Summer & $2060(25.4)$ & $8550(24.6)$ & & - & - \\
\hline Fall & $2031(25.1)$ & $8477(24.4)$ & & - & - \\
\hline Number of visits & $1[1-2]$ & $1[1-2]$ & $<0.01^{\circ}$ & $1.07(1.05-1.1)$ & $<0.019$ \\
\hline
\end{tabular}

ObGyn triage: obstetrics and gynecology triage; ED: emergency department. ${ }^{*}$ Number of visits; ${ }^{\circ}$ Number of patients. Data presented as N (\%). §This group served as the reference group in the multivariate analysis. ${ }^{*}$ chi square test, ${ }^{\circ}$ Wilcoxon rank-sum test, 9 Wald test; Population averaged model: the study population consisted in 42,802 accesses for 28,913 different patients; the average number of visits for each subject was 1.5 , ranging from 1 to 33 . QIC = $40,932, \mathrm{QIC}_{\mathrm{U}}=40,927$. 


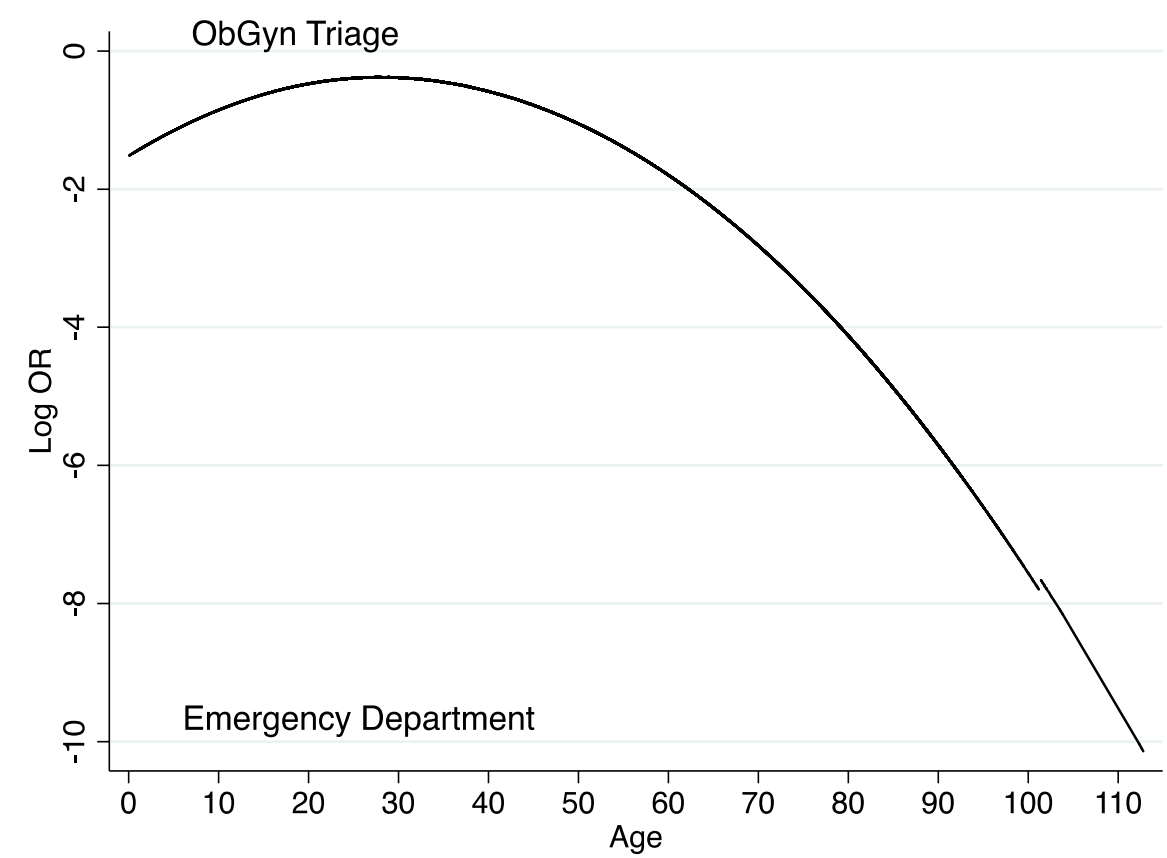

ObGyn triage: obstetrics and gynecology triage. Log OR of referring to the OB/Triage $v s$ the Emergency Department.

Figure 1. Use of emergency services and women's age.

presenting after $8 \mathrm{pm}$ were more likely to be admitted than Caucasian women using emergency services before $8 \mathrm{pm}(p=0.02)$ (Table 3$)$.

\section{Discussion}

As expected, pregnancy and vaginal bleeding were reasons patients more commonly gave for visiting the ObGyn triage than the ED, accounting for more age extremes among emergency medicine users, as opposed to reproductive aged women who preferentially accessed acute female services (Table 1, Figure 1). Interestingly, women presenting to the ObGyn triage had more diurnal and weekday accesses than female emergency medicine patients (Table 1). The National Hospital Ambulatory Medical Care Survey described a time-of-day pattern of ED patients, distinguished by a relatively low level of demand during the night, followed by a precipitous increase starting at about 8 or 9 am, a peak at about noon, and persistently high levels until late evening [26]. Such differences were found to be more pronounced in acute female care. Different factors could contribute explaining such findings: external providers may not have the technology necessary to assess maternal and fetal wellbeing (ultrasound, fetal monitoring), and may have difficulties accommodating the urgent needs of women requiring same day care [27]. When external providers need second opinions from hospital subspecialists (Maternal and Fetal Medicine, Oncology) they may refer their patients directly to triage. Finally, women with acute complaints may consider hospitals the safest place, due to the presence of obstetrician-gynecologists, anesthesiologists and pediatricians, available for emergent surgeries, deliveries, and neonatal resuscitation. 
Almost one third of the visits were by individuals who utilized emergency services two or more times in a year (Table 2). Because EDs recently experienced a dramatic increase in patient volume, interest has focused on a group of individuals who contribute a disproportionate number of visits [28] [29]. Although recurrent utilization of emergency services is often perceived to be a potentially preventable waste of resources, frequent use does not always equate misuse [19] [28] [29]. Previous work showed that recurrent ED users are predominantly women who also heavily rely on other parts of the health care system (especially primary care), presenting with diverse symptoms that often require immediate attention [28] [29]. These findings indicate that ED utilization depends not only on specific medical conditions, but also on patient level factors such as disease burden, accessibility of health care, and intrinsic psychosocial characteristics of the patients themselves [28] [29]. Our findings corroborate such results, as we demonstrated that frequent users of emergency healthcare had multiple complaints, and utilized both the ED and the ObGyn triage, without a specific daily, weekly or seasonal pattern (Table 2). Although more appropriate use of services has been associated with less non-indicated ED visits and lower healthcare costs in smaller studies, with so many individuals making EDs their choice, such services were shown to fill an important niche in the health care [30]. Our findings indicate that ObGyn triage may have a similar role caring for women, especially during pregnancy, when they more frequently experience compelling indications to seek medical assistance (Table 2).

Hospital admission rates further emphasized how obstetrics and gynecology triage contributed to outpatient management of women with acute complaints, as the proportion of inpatients deriving from female acute care services was lower than from ED visits (Table 3). Interestingly, admission rates were higher among non-Caucasians presenting at nighttime (Table 3). Due to more limited staff and testing availability after business hours, physicians might admit women with acute complaints to offer them a rapid diagnostic workup on the following days, as they are less likely to be monitored for worsening symptoms if discharged home. Moreover, immigrants (mainly non-Caucasians) represented a further challenge to outpatient management because of low income, cultural differences, and language barriers that may affect compliance [31].

The strengths of our analysis include the large sample size, the thorough medical records review, the lack of missing data, and the results adjusted for potential confounders. Our study also had some weaknesses. The medical records did not consistently include information about patients who left without being seen, who left against medical advice, or who declined hospital admission. Although the lack of distinction between the obstetric and the gynecology triage units could be considered a limitation of the study, we preferred to classify patients according to their chief complaints, as the aim of our study was to assess the reason prompting urgent visits. Moreover, health services provided by the obstetric triage overlapped to some extent with the work of the gynecology triage, especially when users were pregnant women in the first trimester, or in case 
of high workloads. The model of acute care services described in our study could limit generalizability of our findings to different healthcare settings. However, the goal of our survey was not to identify the ideal care delivery design, but to describe the characteristics of women with acute complaints. Although information on the actual costs of the services provided was not available, patients' copay could reach a maximum of 150 euros for ED visits, 80 euros for gynecology triage visits, while care for pregnant women was free of charge.

Using quality indicators developed in emergency medicine, we showed for the first time that risk factors for "crowding" are more common in obstetrics and gynecology acute care than emergency medicine, as shown by higher diurnal, weekday, and recurrent accesses, at lower hospital admission rates [30] [32]. "Crowding" is one of the most critical problems impacting EDs worldwide, occurring when the number of patients waiting to be seen, undergoing assessment and treatment, or waiting for departure or hospital admission exceeds staffing capacity [30] [32]. Due to crowding, patients experience worse outcomes, while healthcare costs increase significantly. Further research is needed to determine if other ED performance measures, such as time to first contact with a physician, time to hospital admission, and time to discharge, could efficiently measure crowding when applied to obstetrics and gynecology, in order to improve delivery of female healthcare services. In fact, interventions such as the introduction of short stay units, or units that bridge outpatient providers with inpatient services, have successfully reduced crowding and hospital admissions among ED patients, and may also benefit obstetrics and gynecology urgent care [33].

In conclusion, we demonstrated for the first time that obstetrics and gynecology acute care patients significantly differ from emergency department users; our findings may provide a valuable contribution when planning interventions or allocating resources to improve acute female care.

\section{Acknowledgements}

The authors would like to thank Corrado Tartaglia MS, for providing indispensable assistance in data extraction and management.

\section{Conflicts of Interest}

The authors report no conflicts of interest. The authors declare no sources of financial support for the research reported.

\section{References}

[1] Di Renzo, G.C., O’Herlihy, C., van Geijn, H.P. and Copray, F.J. (1992) Organization of Perinatal Care within the European Community. European Journal of Obstetrics Gynecology and Reproductive Biology, 45, 81-87.

[2] World Health Organization (2010) The World Health Report: Health Systems Financing: The Path to Universal Coverage. World Health Organization, Geneva.

[3] Curtis, K.M., Hillis, S.D., Kieke, B.A., Brett, K.M., Marchbanks, P.A. and Peterson, H.B. (1998) Visits to Emergency Departments for Gynecologic Disorders in the United States, 1992-1994. Obstetrics \& Gynecology, 91, 1007-1012. 
https://doi.org/10.1097/00006250-199806000-00026

[4] Nicholson, W.K., Ellison, S.A., Grason, H. and Powe, N.R. (2001) Patterns of Ambulatory Care Use for Gynecologic Conditions: A National Study. American Journal of Obstetrics \& Gynecology, 184, 523-530.

https://doi.org/10.1067/mob.2001.111795

[5] Magriples, U., Kershaw, T.S., Rising, S.S., Massey, Z. and Ickovics, J.R. (2008) Prenatal Health Care beyond the Obstetrics Service: Utilization and Predictors of Unscheduled Care. American Journal of Obstetrics \& Gynecology, 198, 75.e1-e7.

[6] Kumar, V., Gupta, J. and Shehmar, M. (2013) Analysis of an Innovative One-Stop, Hospital-Based, Outpatient Acute Gynaecology Clinic: Model for Taking the Service to Community. Journal of Family Planning and Reproductive Health Care, 39, 292 294. https://doi.org/10.1136/jfprhc-2012-100549

[7] Bourne, T. and Condous, G. (2009) Rationalising Acute Gynaecology Services: Is It Time to Move Away from "Stand-Alone" Early Pregnancy Units? Best Practice \& Research Clinical Obstetrics \& Gynaecology, 23, 575-576.

[8] Haider, Z., Condous, G., Khalid, A., Kirk, E., Mukri, F., Van Castler, B., et al. (2006) Impact of the Availability of Sonography in the Acute Gynecology Unit. Ultrasound in Obstetrics \& Gynecology, 28, 207-213. https://doi.org/10.1002/uog.2801

[9] Huchon, C., Dumont, A., Chantry, A., Falissard, B. and Fauconnier, A. (2014) Triage Using a Self-Assessment Questionnaire to Detect Potentially Life-Threatening Emergencies in Gynecology. World Journal of Emergency Surgery, 13, 39-46. https://doi.org/10.1186/1749-7922-9-46

[10] Risso-Gill, I., Kiasuwa, R., Baeten, R., Caldarelli, I., Mitro, S., Merriel, A., et al. (2014) Exploring the Scope of Practice and Training of Obstetricians and Gynaecologists in England, Italy and Belgium: A Qualitative Study. European Journal of Obstetrics Gynecology and Reproductive Biology, 180, 40-45.

[11] Jacquet, G.A., Foran, M., Bartels, S., Becker, T.K., Schroeder, E.D., Duber, H.C., et al. (2013) Global Emergency Medicine Literature Review (GEMLR) Group. Global Emergency Medicine: A Review of the Literature from 2012. Academic Emergency Medicine, 20, 835-843. https://doi.org/10.1111/acem.12173

[12] Bitterman, R.A. (2009) Medicolegal Issues and Risk Management. In: Marx, J., Hockberger, R. and Walls, R., Eds., Rosen's Emergency Medicine, 7th Edition, Mosby Elsevier, Philadelphia, 2558-2582.

[13] Goldberg, R. and Bornosky, A.R. (2009) Wellness, Stress, and the Impaired Physician. In: Marx, J., Hockberger, R. and Walls, R., Eds., Rosen's Emergency Medicine, 7th Edition, Mosby Elsevier, Philadelphia, 2600-2605.

[14] Madsen, M., Kiuru, S., Castrèn, M. and Kurland, L. (2015) The Level of Evidence for Emergency Department Performance Indicators: Systematic Review. European Journal of Emergency Medicine, 22, 298-305. https://doi.org/10.1097/MEJ.0000000000000279

[15] National Hospital Ambulatory Medical Care Survey: 2010 Emergency Department Summary Tables. http://www.cdc.gov/nchs/data/ahcd/nhamcs_emergency/2010_ed_web_tables.pdf

[16] Guidelines on Personal Data Management in Clinical Studies. http://www.garanteprivacy.it/web/guest/home/docweb/-/docweb-display/docweb/2 $\underline{818670}$

[17] Personal Data Protection Act. http://www.medicoeleggi.com/argomenti000/italia2008/400194-a.htm

[18] Peñacoba-Puente, C., Monge, F.J. and Morales, D.M. (2011) Pregnancy Worries: A 
Longitudinal Study of Spanish Women. Acta Obstetricia et Gynecologica Scandinavica, 90, 1030-1035. https://doi.org/10.1111/j.1600-0412.2011.01208.x

[19] Pan, W. (2001) Akaike's Information Criterion in Generalized Estimating Equations. Biometrics, 57, 120-125. https://doi.org/10.1111/j.0006-341x.2001.00120.x

[20] Cui, J. (2007) QUIC Program and Model Selection GEE Analyses. The Stata Journal, 7, 209-220.

[21] La Calle, E. and Rabin, E. (2010) Frequent Users of Emergency Departments: The Myths, the Data, and the Policy Implications. Annals of Emergency Medicine, 56, 42-48.

[22] Akaike, H. (1973) Information Theory as an Extension of the Maximum Likelihood Principle. In: Petrov, B.N. and Csaki, F., Eds., Second International Symposium on Information Theory, Akademiai Kiado, Budapest, 267-281.

[23] Raftery, A.E. (1995) Bayesian Model Selection in Social Research. In: Raftery, A.E., Ed., Sociological Methodology, Blackwell, Oxford, 111-164. https://doi.org/10.2307/271063

[24] Rigon, F., Bianchin, L., Bernasconi, S., Bona, G., Bozzola, M., Buzi, F., et al. (2010) Update on Age at Menarche in Italy: Toward the Leveling off of the Secular Trend. Journal of Adolescent Health, 46, 238-244.

[25] Henderson, K.D., Bernstein, L., Henderson, B., Kolonel, L. and Pike, M.C. (2008) Predictors of the Timing of Natural Menopause in the Multiethnic Cohort Study. American Journal of Epidemiology, 167, 1287-1294. https://doi.org/10.1093/aje/kwn046

[26] McCaig, L.F. and Burt, C.W. (2004) National Hospital Ambulatory Medical Care Survey: 2002 Emergency Department Summary. Advance Data from Vital and Health Statistics-CDC. National Center for Health Statistics, Hyattsville.

[27] Schuur, J.D. and Venkatesh, A.K. (2012) The Growing Role of Emergency Departments in Hospital Admissions. The New England Journal of Medicine, 2, 391-393. https://doi.org/10.1056/NEJMp1204431

[28] McCarthy, M. (2013) More US Patients Going to Emergency Rooms as Alternative to Primary Care, Report Says. BMJ, 346, f3398. https://doi.org/10.1136/bmj.f3398

[29] Pines, J.M., Asplin, B.R., Kaji, A.H., Lowe, R.A., Magid, D.J., Raven, M., et al. (2011) Frequent Users of Emergency Department Services: Gaps in Knowledge and a Proposed Research Agenda. Academic Emergency Medicine, 18, e64-e69. https://doi.org/10.1111/j.1553-2712.2011.01086.x

[30] Pines, J.M., Hilton, J.A., Weber, E.J., Alkemade, A.J., Al Shabanah, H., Anderson, P.D., et al. (2011) International Perspectives on Emergency Department Crowding. Academic Emergency Medicine, 18, 1358-1370. https://doi.org/10.1111/j.1553-2712.2011.01235.x

[31] Kim, S.W., Li, J.Y., Hakendorf, P., Teubner, D.J., Ben-Tovim, D.I. and Thompson, C.H. (2014) Predicting Admission of Patients by Their Presentation to the Emergency Department. Emergency Medicine Australasia, 26, 361-367. https://doi.org/10.1111/1742-6723.12252

[32] Hoot, N.R. and Aronsky, D. (2008) Systematic Review of Emergency Department Crowding: Causes, Effects, and Solutions. Annals of Emergency Medicine, 52, 126136.

[33] Welch, S., Augustine, J., Camargo, C.A. and Reese, C. (2006) Emergency Department Performance Measures and Benchmarking Summit. Academic Emergency Medicine, 13, 1074-1080. https://doi.org/10.1111/j.1553-2712.2006.tb00282.x 
Submit or recommend next manuscript to SCIRP and we will provide best service for you:

Accepting pre-submission inquiries through Email, Facebook, LinkedIn, Twitter, etc. A wide selection of journals (inclusive of 9 subjects, more than 200 journals)

Providing 24-hour high-quality service

User-friendly online submission system

Fair and swift peer-review system

Efficient typesetting and proofreading procedure

Display of the result of downloads and visits, as well as the number of cited articles Maximum dissemination of your research work

Submit your manuscript at: http://papersubmission.scirp.org/

Or contact ojog@scirp.org 